\title{
Modern institutional framework for reef fisheries management
}

\author{
by Tim Adams, SPC Coastal Fisheries Programme \\ Chapter 13 in "Reef Fisheries Management", edited by Nick Polunin and Callum Roberts, published \\ by Chapman and Hall in 1996
}

\subsection{Introduction}

This chapter describes and comments on the kinds of controls that are instituted over present-day reef fisheries for one reason or another. Chapter 12 has dealt with the traditional management of reef fisheries - management based on long-established precedents and implemented at the community level. Here, traditional management is treated as just one (but often a very significant) component in a continuum of possibilities, ranging from dialogue between individuals through to international conventions. This chapter will not go into great detail about the reasons why management might be imposed, or try to summarise the full range of management measures that might be used (see Munro and Fakahau, 1993a), but will concentrate on the underlying processes and practicalities of managing tropical reef fisheries. Fundamental to this discussion is that the consideration of a fishery is not limited to consideration of the resource only - the human element is crucial (see Hilborn, 1985; Ruddle, Chapter 6 and McManus, Chapter 9). Human beings are, after all, the reason why fisheries management is necessary in the first place.

\subsection{Types of Institution}

Institutions are mechanisms for the formal expression of common principles. They exist to facilitate cooperation among human beings. The institutional framework for reef fisheries management covers a range of increasing levels of agreement:

1. No institutions. Reef fisheries which are not subject to any kind of agreement at all concerning their exploitation are non-existent, although there are many remote reefs where no effective control over fisheries exists. Since the United Nations Convention on the International Law of the Sea legitimised the claims of coastal States to 200-mile Exclusive Economic Zones, even the remotest reefs have become significant as potential EEZ boundary base-points.

2. Agreements among resource users. Many traditional fishery management measures have evolved out of agreements among individuals to maintain exploitation of a shared resource. Such agreements usually occur where there is access to limited areas, or where fishing is carried out by individuals within the same clan, or village. Informal management of this kind is much less effective where the management unit covers a large area, or where the resource users themselves have little in common.

3. Agreements between resource users and resource owners. Again, at the local community level, this is difficult to separate from the previous class since many resource owners are also resource users. A community often controls fishing by outsiders on a certain reef whilst continuing to fish that reef themselves. However, in some societies this is more formalised, with a community leader or committee taking the overall responsibility for controlling exploitation. Such management, where control is at the community level, with the management unit on the scale of an individual reef, and with resource owners in day-to-day contact with resource users, can be extremely effective. Feedback is implicit and the fine-grained nature of the system is well adapted to patchily-distributed resources.

4. Agreements at the provincial, state or national level. Here contact among resource users and resource owners is indirect, mediated by specialists, and where formal, codified procedures are followed. Many modern fisheries are managed at this level, particularly those of the industrialised nations, although this is perhaps more due to the nature of fisheries in temperate water than to the effect of industrialisation on social systems:- temperate and continental shelf fisheries tend to be less patchy than reef fisheries, with a higher biomass concentrated in relatively few major species. As a consequence, management at this broader scale tends to be 
most effective in temperate waters. However, the national level is often the lowest level at which sufficient resources can be pooled to support fisheries research and fundamental conservation measures in developing countries, and is usually the optimum level for controlling commodity export fisheries.

5. Agreements at the regional level. Whilst the geographical region is probably the optimum level for management of highly-migratory species such as tuna, and high-seas fisheries, reef fisheries require a much finer-grained approach to management than can be provided by regional institutions, particularly when sovereignty is purely vested in nations. However, regional-level agreements can be a useful tool in the management of export fisheries and, for small nations, are the most effective level for pooling research resources.

6. Agreements at the global level. There is probably little place for global institutions in direct fisheries management in the foreseeable future. Most fisheries are most effectively managed, or monitored, at the spatial scale of the unit stock yet there are very few marine species where the unit stock can be said to be global in distribution. Industrial fisheries management regimes, which the United Nations has actively promoted, are usually implemented at the regional, or sub-regional, level. International agreements that affect trade, such as the Convention on International Trade in Endangered Species (CITES) and the General Agreement on Trade and Tariffs (GATT) can however have considerable indirect consequences for reef fishery management (Daly, 1993).

- Global consideration of fisheries management issues often means that "economic minority" fisheries, including most reef fisheries, receive a disproportionately small share of attention, and dialogue is monopolised by industrial fisheries. Total global marine fishery production was around 80 million metric tonnes in 1990 (FAO Fisheries Dept., 1992), of which approximately $1 \%$ was derived from reefs. The importance of reef fisheries depends on how it is evaluated. If weighted by the number of economically significant species involved, reef fisheries might be considered as important as many others. Fiji, for example, records commercial fishery statistics for over 100 fin-fish species and nearly 50 reef invertebrates (Fiji Fisheries Division, 1992), whilst the western seaboard of the United States and Canada reports on a total of 31 commercial fish and invertebrate species (FAO Fisheries Dept., 1992). If weighted by the number of people currently dependent on them for their livelihood, reef fisheries would be amongst the most important in the world. If weighted by the number of countries in which reef fisheries are important (many of which are small island countries), consideration of these fisheries would be paramount.

It is difficult to judge the level in the institutional continuum at which the management of a fishery would be most effective. It depends not only on the biology of the target species, particularly the extent of the unit stock (Appeldoorn, Chapter 10), but also on the social organisation of the fishing community targeting that stock (Ruddle, Chapter 6; McManus, Chapter 9). Reef fisheries are probably most effectively managed on a day-to-day basis at the local community level but local communities sometimes have problems in dealing with outsiders without governmental support. Conversely, some invertebrate export fisheries are most cost-effectively managed at the national level, through control of trade outlets, but may require local community cooperation in order to be effective. For example, a total national allowable catch (TAC) for export will not take into account the possibility that this TAC is taken from limited reef areas and not spread across the whole area assumed in the original calculation, unless there is some method of locally certifying the origin of each shipment.

\subsection{Types of Management}

Fisheries management is by no means an exact science. There are too many unsecured variables to make predictions with any hope of accuracy. One way of trying to cope with this is to discount the human element in fishery management and to concentrate research effort on resource management instead. One school of thought says that the human element can be treated simply as a single controllable parameter of the resource-behaviour model. Experience of the resultant "fishery" management regimes in action however tends to suggest otherwise. Such regimes cannot cope with 
market booms caused by the installation of a new airline connection, or a sudden increase in the use of explosives for fishing due to a change in mining methods. Only a very broad information base, a modicum of intuition, and a great deal of flexibility can accomplish that. It is occasionally useful to recall that there is no such thing as a single-species fishery. All fisheries involve at least two species and one of them is Homo sapiens.

A great deal has been written about the management of temperate, shelf and fluvial (and lately, tuna) fisheries, and most of the theories are designed around single- or few-species fisheries targeted by industrial methods. The diversity of edible fishes and invertebrates is much higher in the tropics, and is one of the reasons why tropical near-shore (including reef) fisheries are considered to present the most complex fisheries management problems in the world (Longhurst \& Pauly, 1987; Hatcher et al., 1989). This chapter will not draw on most of the published literature on fisheries management, which does not address reef fisheries. It will be based mainly on the practical experience of the author in attempting to oversee the management of the fisheries of a Pacific small island nation.

To apply temperate-fishery management methods effectively to a reef fishery often costs more than the possible commercial value of the species targeted for management. This rules out any possibility of resource-users eventually bearing the full cost. Most legal measures in place to control reef fisheries in small island countries are low-cost, passive measures. Minimum size limits, enforced mainly at the point of sale, are common, and many countries do not even have a licensing system for domestic commercial fisheries. The recent intensification of research into traditional and community fisheries is welcome since community-level management is potentially far more cost-effective than day-to-day governmental control (Ruddle, Chapter 12) and, being relatively geographically fine-grained, it also has much greater potential to be biologically effective. The study of community fisheries should not be dismissed as the mere recording, for posterity, of obsolete traditions "before they are lost for ever". Local systems are evolving all the time, and the mosaic of different management measures that are introduced by local groups to cope with widespread change constitute an extensive series of experiments in themselves (McManus, Chapter 9). Such "patchworks" are most noticeable with the prosecution of a new fishery (for example, the periodic demand for certain types of invertebrate for export markets).

Adaptive fisheries management operates on the premise that information can be gained about a fishery by observing the result of applying contrasting management measures. Altering the value of one of the "variables" (such as massively increasing fishing effort for one season) and then observing what result this has on the fishery is a type of management by experiment. For such experiments to be effective, the results must be observed. Local communities observe the results of their management changes and adapt accordingly, whilst researchers observe the results of their own management experiments and amend theory accordingly. Scientists however rarely observe the results of local community adaptations. Whilst these adaptations are not scientific they can provide a very cost-effective source of information for the formulation of hypotheses to be tested scientifically.

The fundamental basis of effective institutional fisheries management is feedback, particularly if management involves an element of experiment. Whilst feedback between harvester and manager is implicit in most local communities, more formal monitoring systems are needed if the management institution is broader than the community. Regulation without feedback is useless unless the fishery is completely steady-state and invariable, which is probably never the case.

For reef fisheries there are two contrasting poles of practical management:

1. pre-emptive, or strategic, management. This requires much knowledge about the biology of the target organism(s), about the fishing community, and the effect it will have on the resource. It formulates a model of a fishery based on this prior knowledge and applies management measures to the fishery designed (theoretically) to produce a particular result (usually a certain level of catch) at a future period; and 
2. retrospective, or evolutionary, management assumes no detailed initial knowledge. Fishing occurs under a certain set of rules and the result is observed. If catch rates decline, the rules are made more restrictive, and if catch rates do not decline, the rules can be relaxed. Continued feedback provides (theoretically) an increasingly precise system of management. Adaptive management, in the sense of Walters (1986), is a type of evolutionary management where the set of rules is manipulated to produce an unambiguous and testable "signal" in the fishery.

Both extremes have their limitations. Pre-emptive management requires much expensive research whilst retrospective management is risky. There is a danger, albeit remote, of an extreme set of rules adversely affecting a fishery for years. The more likely danger is that feedback may not come through in time, or that the management system is too inflexible to adapt quickly, leading to sub-optimal levels of catch. Perhaps the most insidious drawback of retrospective management is that it rarely takes account of multi-year climate fluctuations such as the El Niño southern oscillation. Polovina et al. (in press) point out the need for resource managers to heed interdecadal climate events. Recent restrictive amendments to the management plan for the Hawaiian spiny lobster fishery (WPFMC 1991) illustrate how a management plan, based on cycle upswing years, may need drastic revision to account for reduced recruitment during a down-turn.

The ideal management plan will, of course, combine elements of both approaches.

\subsection{Reasons for management}

The most fundamental question of fisheries management is: why manage? The introductory paragraphs on types of management systems assume that the purpose of management is to maintain a steady-state fishery with a constant, economically optimal, catch level for each component species into the indefinite future. However, other goals are often more achievable and these include:-

1. Maintenance of similar total catch levels, but with a changed, or changing, balance of species. Depending on the sequence of fishing methods, this may be due to selective removal of top-level predators allowing an increased biomass of prey-species, with the ultimate climax assemblage consisting of a preponderance of high-mortality species.

2. Maintenance of a cumulative catch over the long term, but via a series of short-term fluctuations. As long as the resource concerned is not too fragile (it is not recommended, for example, for turtles, deep-water snapper, or giant clams), this is a viable low-cost management aim for an export commodity fishery such as sea-cucumber (Adams, 1993). However, long-term cumulative catches are likely to be lower than under a steady-state regime, and it is unlikely to encourage stable investment. Such management is definitely not recommended for a subsistence, or staple-food fishery.

3. Prevention of major damage if the aim of effectively influencing, or fine-tuning, the biological aspects of a fishery is either not possible, or hopelessly expensive. Measures such as minimum sizes for capture, and gear regulations can be designed to provide effective protection to a portion of the stock, and provision can be made for introducing selective bans on threatened species as necessary.

4. Avoidance of conflicts over resource usage or resource ownership by concentrating on managing the human element of the fishery. This could be to protect the rights of certain elements of the population (such as subsistence coastal dwellers), to attract foreign investment, or even to maximise the take-home emoluments of fisheries officials. Such factors are often of far more significance to reef fisheries management than biology.

5. Prevention of overfishing is possibly the simplest aim of management. The definition of overfishing however is difficult (Pauly et al., 1989; Jennings \& Lock, Chapter 8).

We can now consider mechanisms of management. To do this the management regime will be divided into fundamental components of information, regulation, and enforcement. The discussion will concentrate on measures used at the national government and local community levels. 


\subsection{Information sources}

If a fishery is to be managed for a particular purpose, information is essential. Surprisingly this is often overlooked when human and financial resources are allocated by institutions involved in fisheries management. Some reef fisheries are, in fact, managed by inertia, with little reference to changing circumstance.

Information is needed for developing management models, using general systems or primary information. Detail and secondary information about changes with time are also needed for putting management into practice: for fine-tuning the pre-emptive components of the management model, and for adapting to changes in the fishery itself, the latter resulting from the imposition of the management model or from exogenous influences. Information about all of the factors that affect a fishery must be included. The biology of the resource is only one component of the information needs of effective fishery management, which cover the following range:-

1. Feedback from resource users is the most important information linkage to maintain. At the local community management level this comes from day-to-day conversations and semi-formal community meetings, but is not usually documented and is difficult for external researchers and national-level managers to access. More formal types of feedback are catch-returns (not usually feasible for small-scale and subsistence fishing activities) or occasional surveys of landing points and fishing grounds. Such numerical channels of information sometimes become routine to the point of inaccuracy, as harvester's responses "drift" gradually from the standards initially calibrated - for example, a reporting form that measures the landings of reef fish catches by "string" may not take account of changes in the number of fish on the string as marketing methods change. Fisheries officers should also be encouraged to provide intelligence; to report anecdotally on events in the fishery. The most relaxed and gossip-prone offices often have a better idea of how a fishery is performing than those with a slavish devotion to numerical data. They are less able to justify their conclusions however, and a balance must be struck.

2. Feedback from direct resource status monitoring. Most finfish fisheries are not amenable to direct resource status monitoring because the records that are most easily collected, such as catch returns and creel surveys, monitor catch status, not resource status. No fishing gear is completely efficient. Catch rates vary (Dalzell, Chapter 7), and catch per unit effort is often difficult to relate to abundance (Hilborn, 1985). Invertebrates, being relatively sedentary, tend to be more amenable to direct observation and estimates of resource status derived from area surveys are usually more reliable, given equal sampling effort, than those derived from catch monitoring. There are of course exceptions: some invertebrates are cryptic and some fishes are sedentary. Most fisheries departments collect data from fishing only, and should occasionally calibrate the resultant abundance estimates against fishery-independent estimates. Where it is not cost-effective to use fishery-independent methods for resource status monitoring (where the attainment of a useful degree of precision would require an unrealistically large survey effort) and only fisheries data is available, the estimation of effort should not be ignored. Recently, the assessment of tropical fisheries through length frequency sampling has become common and, whilst this reduces the need for fishing effort quantification for stock assessment, it introduces its own set of assumptions, and does not give the fishery manager much information about the human component of the fishery.

3. Feedback from communities is important to local government and broader levels of management. In societies where subsistence fishing is significant, or where reef tenure prevails, government must take account of communities. In many societies regular meetings occur between community leaders and government, but attendance can become extremely timeconsuming for little real return. In such cases the fisheries management institution should arrange people within the community with whom it can liaise regularly.

4. Feedback from theoreticians. Specialists who can take the available information, analyze it, and then predict how a fish stock, a coral reef community, a village society, or even an entire fishery will react are rare at the community or local government level. Since most reef fisheries are in developing countries, fishery modellers and synthesists are not even common at the national 
level. This is unfortunate, since such people need to maintain close contact with fisheries and the actual problems of fishery managers if their work is to maintain relevance. At the same time, feedback from theoreticians is essential to the fisheries management institution. A reasonable model of how target resources behave and interact is necessary to speed up the process of designing and fine-tuning management plans. Management can be completely retrospective, moving slowly towards the optimum by a series of experiments, but this process may take generations. Experience in several regions has shown that the linkage between academic theoretician and reef fishery manager often requires considerable mediation and interpretation. International scientific journals are not accessible to everyone (and are not the quickest way of getting essential information into the public domain), and fisheries-aware information specialists are an extremely desirable commodity to any institution.

- Academic research on coral reef fisheries management often fails to adequately consider invertebrate fisheries. Although only $15 \%$ of the total world catch by weight, invertebrates form nearly $58 \%$ of the total value of the top 8 most valuable species groups in the global catch (calculated from FAO Fisheries Dept., 1992). Invertebrates form over $50 \%$ of the live weight of commercially-marketed catches from Pacific Island coastal (mainly reef) fisheries (Dalzell \& Adams, 1994) and they are usually by far the major portion of reef fishery products for export. They are also a major component of subsistence fisheries, particularly the reef-gleaning subsistence fisheries that are carried out mainly by women and children.

5. Feedback from commerce and the economy can help to predict possible trends in the fishery. In the Pacific islands, $80 \%$ of the total catch is consumed directly by communities (Dalzell \& Adams, 1994). Most reef fisheries are subsistence fisheries, and demand is fairly predictable and slow-changing. However, commercial market information is important because it is the commercial fisheries that cause most of the rapidly-evolving crises in reef fisheries management. Even community-level managers need information on export market trends for certain products.

- Another aspect of feedback from trade, particularly from customs and quarantine services, concerns the need to manage the introduction of exotic marine species. Species introductions for aquaculture are increasing, and the trade in live coral reef fishes for aquaria is diversifying rapidly. Such introductions have the potential not only to disrupt local coral reef ecosystems, but also to introduce exotic parasites and diseases. Unfortunately, facilities for marine quarantine, and even for making basic assessments of the risks of certain introductions, are rudimentary in most developing countries.

Discussion of this issue is outside the scope of this chapter, and the reader is referred to Eldredge (1994) and Humphrey (1994) for further information.

6. Feedback from society. Since most fishery products are eaten, the nutritional preferences of a society are significant and nutritional surveys can often provide supplementary information useful for quantification of subsistence fisheries. A knowledge of human population distributions is sometimes as important as fish population distribution in reef fishery management, and exploitation is almost always higher closer to urban centres. Politics is one of the most significant factors of all in the institutional management of fisheries, although a description of the role of politics would require a volume in itself, and will not be attempted here

7. Feedback from other coastal resource users. Reef fisheries are down-stream of almost all human-influenced coastal processes, and a major task of fisheries management institutions is to make other coastal users aware of the vulnerabilities of reef fisheries. An exception is recreational diving, where commercial spear-fisheries can rapidly deplete the most visible reef fishes and make the remainder wary of divers. Many governments are now looking at broader levels of integration in the management of coastal zones, with opportunities for greatly improved information-flow between different resource users. Integrated coastal zone management committees are likely to be involved in prioritisation of the rights of different resource users, including reef fisheries (McManus, Chapter 9).

8. Feedback from similar fisheries in other areas. The knowledge gained in one area can be very useful in the management of similar fisheries in other areas (Munro and Fakahau, 1993b). Also, fast-developing export fisheries driven by foreign capital tend to move gradually across regions, 
and advance warning of the type of problems encountered can be invaluable. Communication among different national fisheries administrations is already relatively good, with several regional or global meetings available annually to national fisheries staff. Most such meetings are driven by the need for international management of highly migratory species, but since most small-nation tuna fishery managers are also reef fisheries managers, the benefits are more widespread. Regional institutions and newsletters also play a major role in seeking out and sharing relevant experiences (eg. Adams, 1993). Countries where national reef fishery management responsibility has been devolved to the state or provincial level sometimes lose access to this information, since only the national coordinators may attend the meetings, and their priorities may not include reef fisheries.

9. Feedback from the broader natural sciences. Fisheries science is generally considered to be a branch of zoology, but most "hard" fisheries science is actually population ecology, and certain aspects of fisheries stock assessment resemble demography. Fisheries management is broader still (see McManus, Chapter 9), and needs to draw on information and models developed for psychology, meteorology, ethnography, wildlife management, forestry and many other disciplines in order to function well. It is a rare institution indeed that can maintain such diverse linkages effectively.

The word "feedback" has been used in this section instead of the more usual "information" because feedback implies a two-way, or circular, process. Good information systems will return processed, or broader, information back to the people who supply the primary information. Fisheries institutions should supply useful information back to the community that fills in the catch returns and completes the questionnaires, as well as using the information internally. Most survey planning meetings spend all of their time designing a form or stratifying a sample area, with little thought to how the derived information is going to benefit the primary sources. For a regular monitoring activity such feedback is vital, and may even preclude the need for data sources to be forced into cooperation by legislation and expensive enforcement.

A few examples of such feedback may be useful. Individual catch-returns may be compiled into a cartographical summary of fishing effort for that month and sent back to each fishing boat with the next month's catch-return form. An institution may be able to maintain a newsletter or radio broadcast passing useful news, and not just institutional directives, back to the community. A national institution can provide a central point for obtaining export market information. Institutional staff can address community meetings. Unfortunately, information necessary for reef fishery management is sometimes collected only by scientists and hoarded against future publications (Mathews, 1993). All too rarely is the time taken to synthesise, summarise, and turn this information around to the benefit of the primary resource user, yet it would pay considerable dividends in the long term.

All such sources of information should be part of the practical management of reef fisheries. They are necessary both for the models of pre-emptive management, and for the evolution of retrospective management systems. They are necessary both for "hard-science" and for "seat-of-the-pants" management. Information acquisition, management and feedback is probably the most important function of reef fishery management institutions.

\subsection{Regulation}

To most people, regulation means legislation. Unfortunately, it also has a similar connotation to many government-employed reef fishery managers. However, regulation is literally the application of a set of rules to a potentially chaotic situation in order to achieve a desirable result. Quite often it does not require either formal legislation, or intervention by that penultimate arbiter of human dispute, the courts. The rules that make up a fisheries management regime can range from informal guidelines used to decide whether or not to issue a licence to a particular fishing vessel, or unwritten community rules that prevent the fishing of spawning aggregations of certain groupers in certain areas, to international agreements on the use, or not, of certain types of fishing gear to take a particular species on the high seas. 
Available regulatory measures include:

1. Investment guidelines. Developing country governments can offer considerable incentive to investment, particularly of foreign capital. Sustainable long-term productivity of a fishery may however compete with the need for short-term economic growth. Foreign fishing companies may be offered tax concessions and accelerated depreciation to set up business by the ministry responsible for economic planning, whilst the ministry responsible for fisheries is desperately trying to stop over-capitalization in certain high-interest fisheries, often reef fisheries. If there is adequate coordination within government, the fisheries department may be able to take part in the economic planning process and set some of the criteria for encouraging investment related to marine resources, or to issue its own guidelines for investors (eg. Lewis, 1985). Environmental impact assessments (EIA) of new investment in fisheries may provide some safeguards, but are usually activated only for terrestrial developments and usually then only for very large projects. Investment guidelines and EIA can only be used as fisheries management tools before fishing has started however. Once a company has set up business, the permissions to continue operation usually become much less stringent.

2. Fishing license issue criteria. Licences to take fish are usually annual, or seasonal, and can thus be used to help moderate the continued operation of a fishery. Whilst the power to issue licences is a legislated power, it is usually exercised "at the discretion of the licensing officer". Within this discretion licences can be issued according to guidelines mandated by the existing fishery management regime, and non-issuance under certain conditions can restrict the number of people, or companies, which have access. Limited entry will not conserve a resource unless other measures restrict the total catch, but it can help those who are licensed to operate at a profit, and mitigate the economic problems associated with "goldrush" fisheries. Limited entry licensing is not a regulatory method that should be used on subsistence, or diffuse, fisheries.

a. A major reason for setting up a licensing system for a reef fishery is to quantify it. It is useful to census how many people are fishing and what vessels and gear they are using. Such licences are normally issued on request and licence fees tend to be minimal. Fishing licences are less useful as regulatory measures in themselves than as identity cards. But, as they become accepted and widespread, they can assume broader roles, as tickets of admission to certain traditional fishing grounds or for catching certain species. To avoid losing the census value of the original licence, additional licensing systems can be set up to mandate these broader roles.

3. Fishing licence renewal conditions. Guidelines governing the issue, or not, of fishing licences, are measures that can usually be applied only once per year. Once the licence is issued, the owners of that licence can do whatever they want without fear of it being taken away, except on conviction by a court. In general, only courts can rescind ownership of anything. However, if conditions are attached to the licence, the licensing authority does at least have grounds for refusing to renew it if these conditions are contravened. In countries where legal systems are overstressed, and where prosecution of fisheries laws is a low priority, licence conditions can be a powerful incentive for good behaviour.

4. Trade licensing guidelines. Many of the products of reef fisheries do not pass through commercial channels, so trade restrictions are of limited utility. Export fisheries are particularly amenable to such measures and, if export permits are issuable on a per-shipment basis, at the discretion of the licensing officer, a fairly fine level of regulation is possible. Export commodities are channelled through processing points and at ports of entry, and this permits efficient enforcement. In fact, they can be so effectively enforced that institutional staff may sometimes concentrate on these almost to the exclusion of other fisheries.

5. Community regulations. Local and traditional regulation of reef fisheries have been discussed already by Ruddle (Chapter 12). If national or local government institutions fail to acknowledge such systems, they have little hope of effectively managing a reef fishery. Even if complete government ownership of reefs and their resources is assumed, the continuing activities and expectations of the communities that actually fish those reefs must be taken into account. Some exercise of authority at the community level is almost always beneficial. Although the 
entrepreneurialism of a high-ranking individual may dominate the decisions of a small community for long enough to decimate a key resource, such conditions may occur in any institution. Particularly those which are not guided by centuries of precedent.

- Community management is usually beneficial to reef fisheries because it operates at the scale of the individual reef. In small-island countries, where almost all members of the local community make full and regular use of reef resources, anomalies and trends are quickly spotted and corrective action can be quickly taken. The role of government institutions should be supportive, and there should be some designated contact point within the fishing community. Outside support is also useful in arbitration because community decisionmaking is not necessarily harmonious.

- In Fiji, for example, the linkage between community and government is assisted by several factors:

- Government formally recognises the traditional right to exploit reef fisheries by designated communities, although it retains sovereign ownership of the seabed and, by implication, absolute ownership of resources.

- Government formally recognises the right of these communities to recommend restrictions on fishing gear, area, or target species on any licence.

- Government formally records the boundaries of traditional fishing rights areas, and mediates the settlement of such boundaries by agreement between neighbouring communities, or any changes that might subsequently ensue.

- The community can formally nominate one of its number to be an honorary fish warden, with powers to investigate fishing occurring within that area and to escort suspected offenders to the nearest authority.

- Government fisheries officers can not issue a fishing licence to any person who has not already obtained the written permission of the representative of the customary fishing rights area where he intends to fish, and a separate permit must be obtained for each such target area (there are several hundred), each of which may apply a different set of access conditions.

- Government informally recognises the traditional right of the community to exact a levy on outsiders wishing access to the resources of the customary fishing rights area. Cash is often required today, particularly for non-Fijians, but the fulfilment of customary courtesies is important.

- There are regular general meetings between the community administration and government officers, at which fisheries management issues can be aired.

6. Fishing associations and lobbies. These are rare in developing countries, where commercial and recreational fishing is not predominant, but in some cases they can be the non-traditional equivalent of community management systems. Generally, they exist to advance the interests of groups of individuals within the commercial or recreational fishing community, but such associations often have a longer-term view than individuals and, if sufficiently forward-thinking, can be entrusted with many of the regulatory aspects of management. Japan has developed the regulatory role of the commercial fishing association further than most.

7. Government regulations. These are the most absolute form of control. The national legislative system has two main roles in fisheries management. It defines the framework within which other levels of management can operate, and acts as the ultimate resort in cases of dispute. It is unrealistic to expect legislation to define every detail of the management of a reef fishery. Legislative systems must be refined over a period of decades, by trial and error, and by a process of adapting principles from other areas. Legislation as framework, for example, empowers licensing officers to set certain conditions for the issue of fishing licences; it defines the powers of the body which arbitrates customary fishing boundary disputes; or it specifies the type of information that commercial fishermen must supply about their catches. It should not define, for example, the maximum allowable catch of a certain species from a certain reef, or the number of vessels that will be allowed to fish in a certain lagoon, because these management parameters need to be flexible and to change from season to season.

- Legislation defines punishments for infringement of rules, and guides legislative authority in deciding guilt. One aspect of this dispute-settlement is that legislation 
should also provide some measure of protection for the individual against illinformed, arbitrary, or corrupt decisions by those in charge of fisheries management. For example, it is safer that committees decide on the allocation of licences than individuals, and it is advisable to make financial procedures explicit. If no fee is to be charged for a certain service, then the legislation should make this clear.

8. International access agreements. Agreements between governments to allow access of fishing vessels from one country to the resources of another are rare for reef fisheries. Despite the suspicion with which foreign tuna vessels under international agreements are still often regarded, most foreign reef poaching today is by boats that are either unlicenced or individually licenced. Few reef fisheries are large-scale, thus few governments consider it worthwhile to regularise the activities of any of its reef fishing vessels that range too widely. Remote reefs subject to a high degree of extra-national exploitation thus currently have little hope of ever being effectively managed, short of posting a gunboat on permanent duty.

9. Regional agreements. These are usually agreements between nations for a common purpose, such as improving trade. If they involve reef fishery products, they can also be utilised in a management regime. In theory, groups of small nations can thereby gain sufficient economic clout to control the supply of a rare resource, to obtain the highest price whilst maximising longterm yields. In practice, the effort involved is only worthwhile for a very high unit-value resource. A regional marketing agreement is currently being considered for black pearls (Pinctada margaritifera) in eastern Polynesia, for example, an annual trade currently worth nearly US\$50 million.

Reef fisheries management thus has a variety of regulatory options to consider. In general, community-level regulation is considered to be both the most cost-effective and the most immediately practical for countries which maintain a high proportion of subsistence and small-scale fisheries. National fisheries legislation can empower and support community management without necessarily giving up sovereignty over resources. The main need for primary government regulation is in previously unexploited fisheries, in industrial fisheries where the fate of entire groups of resources may be in the hands of a few company managers, and in fisheries where unwise exploitation in one reef area (for example, of nesting or spawning aggregations) can severely affect future fisheries in another community's area.

Formal management plans are becoming increasingly popular for reef fisheries. Even if formalisation is not possible, or warranted, every fisheries department should informally maintain a set of written management policies, and update them occasionally in the light of experience, even if only to harmonise the decisions of different officers, or successive heads of department. For occasional reef fisheries these plans might consist of the single phrase, "Leave decisions to the community", where it is the community that benefits from fishing and which would suffer if a resource is imprudently managed. For other fisheries, particularly export fisheries, these plans may be more codified and complex, or even formally legislated, but they should all have one thing in common: they should make allowance for future change.

\subsection{Enforcement}

Regulations are almost useless if they cannot be enforced. The most biologically appropriate management plan - the regime that is most likely to maintain the resource at maximum levels of longterm productivity - will not function if the human element of the fishery cannot be induced to comply with it. Compliance is always more desirable than enforcement, and regulations should be designed with this in mind. For example, it is a lot easier for the fishing community to comply with a minimum size limit for taking certain species of fish if the minimum allowable mesh size for gill-nets maximises the escape of the prohibited size-classes. Such a regulatory interaction has been overlooked in at least one country. "Compliance facilitation" is particularly important in small-island countries where law enforcement staff may be related to a significant proportion of the fishing community, and where family ties may prevent the arrest or censure of a relative (eg. Berg \& Olsen 1989). 
Governmental enforcement of regulations is not easy since reef fisheries are usually small-scale, with many harvesters landing an extremely heterogeneous mix of species at a multitude of landing points. Enforcement of reef fishery regulations has more similarity to temperate water sport fisheries than to industrial fisheries. As mentioned previously, "industrial" methods of management are relatively costly, particularly for subsistence fisheries. As a result, many developing country governments play little part in the active management of reef fisheries, and those regulations in place are mainly passive, with occasional deterrent enforcement. Many of these countries also have some measure of community control of fisheries in place, whether acknowledged by government or not.

Many of the enforcement activities of government fisheries officers are directed at fish traders. Traders are usually less numerous than harvesters and are thus a convenient "bottleneck" at which to maximise the effectiveness of scarce enforcement resources. Traders are vulnerable to inspections for contravention of size limits, or out-of-season or forbidden species, and will not normally buy such produce from the fishing community if prosecuted too often. The effects of regulation thus eventually filter down to the target community. Where a species is much sought after and subject to heavy commercial competition, the harvester may force the trader to purchase the illegal by-catch in order to acquire the legitimate commodity. Such cases are a signal for enforcement to move out into the fishing community: either community management is not working, or the human population is outstripping the carrying capacity of its local reef environment.

Community-appointed fish wardens, recognised and empowered by government, can be a very useful tool toward enforcement of reef fishery regulations, both traditional and modern. Very often, the authority of the post itself is sufficient reward for part-time activity, particularly as the warden would normally be out fishing for subsistence purposes anyway. If expenses need to be met, these should preferably be administered by the community out of levies charged for access, otherwise government may end up employing more administrative staff than it would have invested in enforcement officers. Such wardens should not be neglected, or taken for granted, and should be able to take part in regular consultations with the local fisheries officer, and in annual meetings.

If biologically-appropriate management measures are also appropriate to the human element of the fishery, they will be easier to comply with and require less enforcement. Most traditional measures, by their very nature, are appropriate to the community, but governmental fishery managers must not rely blindly on community reef fishery management, especially where communities are under stress. Immigration has obvious destabilising effects on long-established communities. Emigration and urban drift have more insidious consequences, where expectations of future entry to the cash economy by one's children may undermine any desire to conserve resources for the next generation. It may become more important to acquire cash to pay for schooling than to practise sustainable fishing.

If there is no community management in operation, the appropriateness of proposed regulations should at least be tested on the community before they are committed to legislation. If regulations are issued as a set of guidelines and tried, then discussed, with various fishing communities, it will quickly become apparent which suggestions the harvesters will be more inclined to follow. For those measures where compliance is not easy, but which it is still considered essential to enforce, incentives for compliance can be considered. For example, duty-free fuel for small-scale fishermen who voluntarily complete catch-return forms is an incentive that is used by the Vanuatu government. Some fisheries departments supply subsidised ice as an incentive to taking out a fishing licence, and others may subsidise the price of larger-mesh gill-nets in an effort to reduce the catch of immature fish. Whilst these incentives are positive measures to assist enforcement, they should be used with caution. Government subsidies may prevent future private-sector development and government may be forced to supply fishing gear, or ice, for ever after.

Another aspect of enforcement is bribery. Only three months after appointment, the Secretary to the Department of Fisheries and Marine Resources in Papua New Guinea told a meeting of lawenforcement and surveillance officers that he had already been offered (and turned down) a total of 
US\$23,000 in bribes (Anon., 1993). The potential for the unequal distribution of favours, in return for personal gain, is inherent in every system of authority. In some societies, "extra-curricular" fees are the norm, and are so overt that they cannot really be considered corruption. Such fees, like tips or gratuities, may even be taken into account when setting the basic wage for institutional officers. In some societies, a token gift customarily accompanies any request to authority, and a failure to make this gesture is considered unmannered. True corruption is when individuals use their positions of privilege, or authority, to favour one applicant over another in return for personal gain. Where a reef fishery management regime is designed to limit the number of licences issued in accordance with certain guidelines that advance the aims of the management regime, the presence of individuals who issue permits in order to advance their own personal aims can entirely destroy that regime.

Such corruption is difficult to pin-point and even more difficult to prove. Extreme security of tenure is a feature of many government jobs, and a corrupt officer is difficult to remove. One method of countering such problems, where suspected, is to make enforcement and inspection officers work as teams, with rotating membership.

Where human resources for enforcement are scarce, there is often the temptation to use research staff to assist in supplying information towards arrests, or even in active enforcement. This should be avoided. Information is as essential to management as enforcement and much information is voluntarily provided. Neither the fishing community nor traders will be cooperative in talking to someone who may arrest them, or who may lead to them paying more tax. Information and enforcement functions of reef fishery management should be exercised by separate institutions, or at least by physically separate branches of the same institution.

\subsection{Interactions amongst the fishing community, managers and scientists.}

Distinctions between the fishing community, managers and scientists are often blurred in the context of tropical reef fisheries. Harvesters are often part of local community management or may own some component of the reef or resource themselves. Shortages of skilled human resources mean that government fisheries scientists often fulfil many of the tasks of fishery managers, short of enforcement. The two main types of interaction are conflict and cooperation.

\subsubsection{Conflict}

Conflict between the fishing community and government managers can occur because measures are not usually introduced until a resource is demonstrated to be overfished, and catch or effort has to be cut. Management costs money, therefore there is a natural tendency not to exercise it until it is absolutely necessary, and even then there may be political pressures to avoid effective action (eg. Aiken \& Haughton, 1990; MacKenzie, 1993). Although commercial fishers, and particularly entrepreneurs, may demur, it is always more desirable to approach the level of optimum yield (or the point beyond which "overfishing" takes place) asymptotically. The conflicts generated by the loss of entrepreneurial expectations are always less than the conflicts involved in trying to cut back an overcapitalised fishery.

Avoidance of extreme conflicts can be a powerful argument to convince senior civil servants to promote measures in advance of actual problems in the fishery. One of the advantages of retrospective management in this regard is that it evolves. The initial management plan can be a simple framework, concentrating mainly on information feedback and requiring minimal investment in enforcement, and thus be relatively painless to introduce. If sufficient flexibility is incorporated, the plan can become more or less stringent as necessary, by small increments if monitoring is sufficiently comprehensive.

Tension between managers and fisheries scientists tends to occur because managers are obliged to maintain an holistic approach to the problem of fisheries management. Scientists need to break the problem down into smaller parts that are amenable to quantification. At the very least, they will separate the resource aspects from the broader problem, particularly its human elements. The 
recommendations of fisheries scientists may thus be different from what managers intuitively feel is best, given the many other factors under consideration, but for which they have no other source of "hard" evidence to justify their intuition. Evolutionary management may provide some reconciliation, by allowing managers to test their feelings whilst scientists can rigorously observe the results of the experiment and fine-tune the theory.

The need for managers often to make sweeping, or rapid, decisions based on minimal evidence also conflicts with the tendency of scientists to hedge all opinions about with provisos. There are many fishery management meetings where the scientists are accused of "sitting on the fence". Scientists occasionally over-compensate, and present wild guesses as justified conclusions, but this is rare. To mitigate such conflicts, scientists should try to present an estimate of confidence in every presentation of results. Even if an estimate of, say, biomass is, to all intents and purposes, inconclusive, to say that it is $95 \%$ likely that the real result is within $70 \%$ of, say, 25,000 tonnes (7,500 - 42,500 tonnes) may at least divert any accusations of "sitting on the fence". This is particularly so if the scientist can then point out that a $10 \%$ increase in research funding would probably improve this confidence interval to less than 20\% (20,000-30,000 tonnes). However, some statistical methods currently employed in fisheries science lack any theoretical method of quantifying a level of confidence in the result. Even empirical methods of estimating confidence may take an impossible amount of computer time for the more complex models.

\subsubsection{Cooperation}

Conditions for fostering good relations, or at least understanding of the aims of every group involved should be inherent in every institutional framework for fisheries management. This principle is automatically taken into account in most modern institutions; indeed, some new institutions attempt to go so far in fostering cooperation that they lose efficiency.

Meetings, in the form of staff meetings, annual institutional meetings, community meetings, seminars and workshops, summits, industry-government councils, fishing industry advisory boards, integrated coastal zone planning meetings, regional and international fisheries meetings etc., can all take their toll on the work programme if not managed properly. The time spent at meetings is an investment, and there must be clear returns on that investment.

Some apparent tension between departments may even be desirable under certain conditions. For example, fishers and traders must see a clear demarcation between enforcers and information gatherers. However, it is easy for modern fisheries management institutions, particularly those with a strong enforcement role, to begin demanding information as a right. Whoever coined the term "civil servant" for a government officer was of an optimistic disposition.

Cooperation is a multi-faceted process, and information is one of its main expressions. One of the main short-comings of government in fisheries management is that there is often poor communication between different departments. There must be mechanisms to discuss and resolve inter-departmental conflicts at the technical level. In many countries departments only communicate at the apex, through the chain of command, and the apex is not necessarily aware of all that is happening further down in the hierarchy. Apart from general administrative issues, government departments responsible for reef fisheries management interact with departments responsible for such functions as economic planning, rural development, environment, customs, police, ports and shipping and legal drafting. Without dialogue departments will develop dissimilar attitudes towards fisheries if they do not have access to appropriate information. For example, economic planners usually consider fisheries in terms of their potential for short-term economic growth, and their views are extremely influential in setting overall government policy. Conversely, environment departments have a conservative attitude, or occasionally distaste, towards exploitation of natural resources and may try to relieve local communities of all management decision-making capacity. 
Fisheries management is not always a popular pretext in itself for calling regular inter-departmental technical meetings, and the recent trend towards inter-disciplinary coastal zone and environmental planning provides useful opportunities to open general discussion on fisheries management issues. The documents resulting from the 1992 United Nations Conference on Environment and Development (UNCED), particularly Agenda 21 Chapter 17, provide a framework for considering fisheries management in the broader context (Anon., 1992). Programme area D is of particular interest. Reef ecosystems are identified as being critical habitat areas, where states should accord the highest priority to providing "necessary limitations on use", whilst taking into account the knowledge and interests of local communities and small-scale artisanal fisheries. As with the United Nations Law of the Sea Conferences, arguments over the exact interpretation of the output of UNCED will occupy institutions for years to come.

\subsection{References}

Adams, T. J. H. (1993) Management of bêche-de-mer (sea cucumber) fisheries. Bêche-de-mer Special Interest Group Information Bulletin, 5, 15-21. (South Pacific Commission, Nouméa, New Caledonia).

Aiken, K. A. and Haughton, M. O. (1990) Regulating fishing effort: the Jamaican experience. Proceedings of the 40th Gulf and Caribbean Fisheries Institute Meeting, 139-150.

Anonymous (1992) Agenda 21. Proceedings of the United Nations Conference on Environment and Development, Rio de Janeiro, 3-14 June 1992. United Nations, New York, U.S.A.

Anonymous (1993) Fisheries "bribes" in PNG. South Seas Digest 13 (7) (18th June).

Berg, C. J. Jr. and Olsen D. A. (1989) Conservation and management of queen conch (Strombus gigas) fisheries in the Caribbean, in Marine Invertebrate Fisheries: Their Assessment and Management, (ed J. F. Caddy), John Wiley \& Sons, New York.

Dalzell, P. J. and Adams, T. J. H. (1994) The present status of coastal fisheries production in the South Pacific Islands. South Pacific Commission 25th Regional Technical Meeting on Fisheries Working Paper 8, South Pacific Commission, Nouméa, New Caledonia.

Daly, H. E. (1993) The perils of free trade. Scientific American, November 1993, 24-29.

Eldredge, L. G. (1994) Introductions of commercially significant aquatic organisms to the Pacific Islands. Inshore Fisheries Research Project Technical Report 6. South Pacific Commission, Nouméa, New Caledonia. 120pp

FAO Fisheries Department (1992) Review of the state of world fishery resources. Part 1. The marine resources. FAO Fisheries Circular 710, Rev.8, Part 1. Food and Agriculture Organisation of the United Nations, Rome, Italy. 114pp.

Fiji Fisheries Division (1992) Annual Report 1991. Ministry of Primary Industries, Suva, Fiji.

Hatcher, B. G., Johannes, R. E. and Robertson, A. I. (1989) Review of Research Relevant to the conservation of shallow tropical marine ecosystems. Oceanography and Marine Biology Annual Review, 27, 337-414.

Hilborn, R. (1985) Fleet Dynamics and Individual Variation: Why some people catch more fish than others. Canadian Journal of Fishery and Aquatic Science 42, 2-13.

Humphrey, J. D. (1994) Risks associated with movements of marine animals in the South Pacific. Inshore Fisheries Research Project Technical Report 7. South Pacific Commission, Nouméa, New Caledonia. 50pp.

Lewis, A. D. (1985) Fishery Resource Profiles: Information for Development Planning. Fisheries Division, Ministry of Primary Industries, Government of Fiji. 90pp.

Longhurst, A. R. and Pauly D. (1987) Ecology of Tropical Oceans. Academic Press, San Diego, USA. 408pp.

Mathews, C. P. (1993) On the preservation of data. NAGA, The ICLARM Quarterly April-July 1993, $39-41$

MacKenzie, D. (1993). Europe's fishing rules slip through the net. New Scientist 1883, 7

Munro, J. L., and Fakahau, S. T. (1993a) Management of Coastal Fishery Resources, in Nearshore Marine Resources of the South Pacific, (eds A. Wright and L. Hill), pp 55-72, Forum Fisheries Agency, Honiara, Solomon Islands. 
Munro, J. L., and Fakahau, S. T. (1993b) Appraisal, Assessment and Monitoring of Small-Scale Coastal Fisheries in the South Pacific, in Nearshore Marine Resources of the South Pacific, (eds A. Wright and L. Hill), pp 15-53, Forum Fisheries Agency, Honiara, Solomon Islands.

Pauly, D., Silvestre, G. and Smith, I. R. (1989) On development, fisheries and dynamite: a brief review of tropical fisheries management. Natural Resource Modeling 3 (3), 307-329.

Polovina, J. J., Mitchum, G. T., Graham, N. E., Craig, M. P., DeMartini, E. E. and Flint, E. N. (in press) Physical and biological consequences of a climate event in the Central North Pacific. Fisheries Oceanography 3 (1).

Walters, C. J. (1986) Adaptive Management of Renewable Resources. MacMillan, New York, USA.

WPFMC (1991) Amendment 7: Fishery Management Plan for the Crustacean Fisheries of the Western Pacific Region. Western Pacific Fisheries Management Council, Honolulu, Hawaii. 110pp. 